\title{
CRESCIMENTO INICIAL DO MELOEIRO EM FUNÇÃO DA APLICAÇÃO DE BIOFERTILIZANTES NO CULTIVO ORGÂNICO
}

\author{
Géssica dos Santos Batista ${ }^{1}$, Juliana Leite da Silva ${ }^{1}$, Daniel Nunes Sodré Rocha ${ }^{1}$, Almir Rogerio \\ Evangelista de Souza $^{2}$, Jairton Fraga Araujo ${ }^{1}$, Alessandro Carlos Mesquita ${ }^{1}$
}

\begin{abstract}
RESUMO - A agricultura orgânica ocupa um crescente espaço no mercado de produtos agrícolas global. Neste modelo de produção a utilização de formas alternativas de adubação a exemplo de biofertilizantes líquidos para uso via solo, tem demonstrado viabilidade econômica e sustentabilidade ambiental, substituindo com eficiência o uso de fertilizantes artificiais. O objetivo do trabalho foi avaliar o crescimento inicial do meloeiro (Cucumis melo L.) cv. Gold Mine submetido a diferentes doses de biofertilizantes em cultivo orgânico. Os tratamentos foram obtidos a partir da diluição de dois biofertilizantes (I e II) formulados com minerais naturais e esterco caprino fresco, como fontes de macro e micronutrientes, água, leite e melaço para multiplicação de microorganismos, seguido da aplicação via solo após uma primeira diluição obtida através do volume de $2,5 \mathrm{~L}$ de biofertilizante e 2,5 L de água, totalizando $5 \mathrm{~L}$ da solução. A partir desta solução, os biofertilizantes foram diluídos em diferentes proporções: proporção de 5\% (300 mL do bio $+2,7 \mathrm{~L}$ de água); $10 \%$ (600 mL do bio +2,4 L de água); $15 \%$ (900 mL do bio + 2,1 L de água); $20 \%$ (1200 mL do bio + 1,8 L de água); $25 \%(1500$ $\mathrm{mL}$ do bio + 1,5 L de água); que foram aplicados via solo semanalmente. As variáveis avaliadas foram: diâmetro do caule, comprimento do ramo, número de folhas, clorofila ( $a$ e $b$ ) e área foliar. Para os resultados obtidos verificaram que a cultura do meloeiro apresentou resposta positiva ao uso do biofertilizante II em todas as variáveis analisadas, recomendando a dosagem de $15 \%$ do produto.
\end{abstract}

Palavras chave: físico-química, microbiológica, potabilidade.

\section{INITIAL GROWTH OF MELON AS A FUNCTION OF BIOFERTILIZER APPLICATION IN ORGANIC CULTIVATION}

\begin{abstract}
Organic agriculture occupies a growing space in the global agricultural product market. In this production model the use of alternative forms of fertilization such as liquid biofertilizers for use in soil has shown economic viability and environmental sustainability, effectively replacing the use of artificial fertilizers. The objective of this work was to evaluate the initial growth of melon (Cucumis melo L.) cv. Gold Mine submitted to different doses of biofertilizers in organic cultivation. The treatments were obtained from the dilution of two biofertilizers (I and II) formulated with natural minerals and fresh manure, such as macro and micronutrients sources, water, milk and molasses for multiplication of microorganisms, followed by soil application after a first dilution obtained through the volume of $2.5 \mathrm{~L}$ of biofertilizer and $2.5 \mathrm{~L}$ of water, totaling $5 \mathrm{~L}$ of the solution. From this solution, the biofertilizers were diluted in different proportions: proportion of $5 \%$ (300 $\mathrm{mL}$ of bio $+2.7 \mathrm{~L}$ of water $) ; 10 \%(600 \mathrm{~mL}$ of bio $+2.4 \mathrm{~L}$ of water $) ; 15 \%(900 \mathrm{~mL}$ of bio $+2.1 \mathrm{~L}$ of water $)$; $20 \%(1200 \mathrm{~mL}$ of bio $+1.8 \mathrm{~L}$ of water $) ; 25 \%(1500 \mathrm{~mL}$ of bio $+1.5 \mathrm{~L}$ of water $)$; which were applied via soil weekly. The evaluated variables were: stem diameter, branch length, number of leaves, chlorophyll (a and $b$ ) and leaf area. For the results obtained, it was verified that the melon crop presented a positive response to the use of the biofertilizer II in all analyzed variables, recommending the dosage of 15\% of the product.
\end{abstract}

Keywords: Cucumis melo L., nutrients, organic agriculture.

\footnotetext{
${ }^{1}$ Universidade do Estado da Bahia. E-mail para correspondência: gessicabatista787@gmail.com

${ }^{2}$ Professor do Instituto Federal de Alagoas
} 


\section{INTRODUÇÃO}

O cultivo do meloeiro (Cucumis melo L.) está presente em praticamente todas as regiões do país, com destaque para a região semiárida do Nordeste, onde o cultivo é desenvolvido em grande parte pela agricultura familiar. Os estados que se destacam na produção são: Rio Grande do Norte, Ceará, Pernambuco e Bahia, os quais contribuem com $95 \%$ da produção nacional (Anuário, 2017). Em 2017, o Brasil exportou cerca de 233,0 mil toneladas de melão, gerando receita de US\$162,9 milhões (Anuário, 2018).

No polo agrícola do submédio Vale do São Francisco, os municípios de Petrolina, Santa Maria da Boa Vista e Floresta em Pernambuco; além de Juazeiro e Curaçá no estado da Bahia, abrangem área de cultivo de aproximadamente 2.000 ha, principalmente cultivada em pequenas áreas utilizando mão de obra familiar (Agrianual, 2018).

No Brasil as principais variedades de melão exploradas são do tipo Pele de Sapo, Amarelo, Cataloupe e Gália. Sendo que nos últimos anos os híbridos vêm sendo preferidos pela sua maior resistência a pragas e melhores produtividades, além de uniformidade dos melões (Lima et al., 2017). O Brasil que antes era tido como um país importador de melão basicamente da Espanha para abastecimento do mercado interno, passou a se destacar na produção desta fruta nas últimas décadas, deixando o status de importador para ser exportador (Ibraf, 2018).

Dados da Agência Brasileira de Promoção de Exportações e Investimentos mostram que o crescimento do mercado de orgânicos no Brasil, no ano de 2017, foi de 25\%, movimentando cerca de R $\$ 2,1$ bilhões (ApexBrasil, 2017). Isso mostra como os consumidores são cada vez mais exigentes e a demanda por alimentos orgânicos não param de crescer.

Com o aumento da população mundial, houve maior demanda por alimentos, fibras e combustíveis, surgindo à necessidade de atenção especial a essas expectativas num curto prazo, de maneira eficiente e lucrativa sem custar danos ao meio ambiente. O uso indiscriminado de pesticidas e fertilizantes químicos altamente solúveis nas culturas têm contribuído para o aumento nos níveis de degradação e empobrecimento dos solos, acarretando na redução da produção agrícola e da biodiversidade nos agroecossistemas, além de fazer mal a saúde humana (Alves et al., 2012).
Desse modo a agricultura orgânica, vem se destacando mundialmente, por ser um modelo que exclui totalmente o uso de moléculas químicas, ganhando espaço no contexto socioambiental, trabalhando as formas de melhoria de vida para o homem sem degradação do meio ambiente (Queiroga et al., 2016).

Neste contexto os biofertilizantes vêm sendo utilizados como uma alternativa econômica e ambiental, por serem fontes orgânicas em cultivos agrícolas, estimulando o crescimento das raízes e desenvolvimento das plantas de forma geral, substituindo assim o uso de fertilizantes minerais (Moraes \& Oliveira, 2017).

Os biofertilizantes são definidos como produtos que contêm componentes ativos ou agentes biológicos capazes de atuar, direta ou indiretamente sobre as plantas cultivadas, melhorando o desempenho da produção, e, que sejam isentos de substâncias proibidas pela regulamentação de orgânicos (Mapa, 2012). A agricultura orgânica resulta do desenvolvimento de sistemas de produção que analise o manejo conservacionista do solo e o aporte de nutrientes oriundos de fontes renováveis, com apoio de resíduos orgânicos localmente disponíveis, de origem vegetal e animal (Lopes, 2014)

Finatto et al. (2013) relatam que o adubo orgânico é constituído de resíduos de origem animal e/ou vegetal, que, após a decomposição, resulta em matéria orgânica. A compostagem, adubação verde, uso de estercos e de biofertilizantes são os exemplos de adubos orgânicos mais conhecidos e viáveis economicamente.

Diante de todo contexto supracitado, o presente trabalho objetivou avaliar o crescimento inicial do meloeiro (Cucumis melo L.) cv. Gold Mine submetido à adubação orgânica oriunda de dois diferentes tipos de biofertilizantes, com diferentes dosagens aplicadas semanalmente.

\section{MATERIAL E MÉTODOS}

O trabalho foi conduzido no campo experimental do Centro de Agroecologia, Energias Renováveis e Desenvolvimento Sustentável - CAERDES do Departamento de Tecnologia e Ciências Sociais da Universidade do Estado da Bahia - (UNEB), no período de setembro a dezembro de 2017, no município de Juazeiro-BA (09²5'43.6"S, 40³2' $\left.14^{\circ} " \mathrm{~W}, 384 \mathrm{~m}\right)$. O clima da região é classificado, segundo Köeppen (1948), como tipo Bswh, que corresponde a uma região semiárida 
quente, com precipitação pluviométrica e média anual de $484 \mathrm{~mm}$. Os dados meteorológicos médios para o período dos experimentos, bem como a análise de solo da cultura, são apresentados nas Tabelas 1 e 2, respectivamente. A ordem de solo da área experimental é classificada como Neossolo Flúvico Psamítico, de textura franco-arenosa (Embrapa, 2013).

O delineamento experimental adotado foi o de blocos completos casualizados, com quatro repetições, sendo representada por uma parcela contendo 5 plantas por bloco e os tratamentos dispostos em esquema fatorial $5 \times 2$ (concentrações de biofertilizantes x tipos de biofertilizantes, respectivamente). Os tratamentos foram obtidos a partir da diluição do biofertilizante - I e biofertilizante - II em água, sendo que, a diluição foi obtida através do volume de 2,5 L de biofertilizante e 2,5 L de água, totalizando $5 \mathrm{~L}$ da solução. A partir desta solução, os biofertilizantes foram diluídos em diferentes proporções: proporção de 5\% (300 mL de bio $+2,7 \mathrm{~L}$ de água); $10 \%$ (600 $\mathrm{mL}$ de bio $+2,4 \mathrm{~L}$ de água); $15 \%$ (900 mL de bio + 2,1 L de água); 20\% (1200 $\mathrm{mL}$ de bio $+1,8 \mathrm{~L}$ de água); $25 \%$ (1500 $\mathrm{mL}$ de bio + $1,5 \mathrm{~L}$ de água); que foram aplicadas via solo semanalmente.

Os dois biofertilizantes foram produzidos no Centro de Agroecologia, Energias Renováveis e Desenvolvimento Sustentável - CAERDES no qual o biofertilizante I apresentava em sua composição: Açúcar mascavo, água não clorada, leite cru, enxofre ventilado (puro) e cinzas e o biofertilizante II possuía em sua composição, conforme adaptação da prática descrita por Zamberlam \& Froncheti (2001): esterco caprino fresco (adaptação), leite cru; açúcar mascavo água não clorada; cinzas; sulfato de zinco; calcário dolomítico; enxofre ventilado (puro); sulfato de magnésio; fosfato de cálcio bibásico; molibdato de amônio (adaptação); sulfato de cobalto; sulfato de manganês; sulfato de cobre; bórax; termofosfato (adaptação); Cofermol (cobalto, ferro e molibdênio) e fosfato natural de Irecê (adaptação).

A cultivar utilizada foi à variedade de melão "Gold mine" do tipo Amarelo, sendo que a semeadura foi realizada em bandejas contendo substrato $(50 \%$ de latossolo eutrófico $+50 \%$ de composto) e após 15 dias, as plântulas, foram transplantadas para o campo. As aplicações dos biofertilizantes foram realizadas semanalmente, 10 dias após o transplantio, onde cada planta recebeu $125 \mathrm{~mL}$ da solução preparada de acordo com os tratamentos supracitados por um período de nove semanas. Após o transplantio, as irrigações foram realizadas diariamente, com base na evapotranspiração da cultura, utilizando-se o coeficiente para a cultura do melão (Kc) (Allen et al., 1998).

As avaliações de crescimento das plantas foram realizadas aos 21 , 36, 51 e 66 dias após o transplantio (DAT), analisando-se as seguintes variáveis: diâmetro do caule (DC) utilizando um paquímetro digital, comprimento do ramo $(\mathrm{CR})$ através de régua milimetrada, número de folhas (NF), a área foliar foi determinada

Tabela 1 - Valores médios mensais de temperatura máxima, média e mínima do ar $\left({ }^{\circ} \mathrm{C}\right)$ precipitação pluviométrica $(\mathrm{mm})$ e radiação solar global na época de cultivo do melão fertirrigado

\begin{tabular}{lccccc}
\hline Meses & \multicolumn{3}{c}{ Temperatura $\left({ }^{\circ} \mathrm{C}\right)$} & Precipitação $(\mathrm{mm})$ & Radiação solar globalMJ m-2 dia $^{-1}$ \\
\hline & Máxima & Média & Mínima & & \\
\cline { 2 - 4 } setembro & 33,7 & 30,6 & 19,9 & 3,0 & 21,4 \\
outubro & 36,6 & 34,2 & 21,8 & 0,0 & 25,6 \\
novembro & 38,6 & 34,9 & 23,6 & 15,8 & 24,8 \\
dezembro & 38,6 & 34,7 & 24 & 31,0 & 24,1 \\
\hline
\end{tabular}

Tabela 2 - Análise química do solo da área experimental, de 0 a 0,3 m, antes do inicio do experimento

\begin{tabular}{|c|c|c|c|c|c|c|c|c|}
\hline Profundidade (m) & $\mathrm{MO}^{\mathrm{I}}$ & $P$ & $\mathrm{~K}^{+}$ & $\mathrm{Na}^{+}$ & $\mathrm{Ca}^{+2}$ & $\mathrm{Mg}^{+2}$ & $\mathrm{Al}+\mathrm{H}$ & $\mathrm{pH}$ \\
\hline \multirow{2}{*}{$0-0,30$} & $\mathrm{~g} \mathrm{~kg}^{-1}$ & $\mathrm{mg} \mathrm{dm}^{-3}$ & \multicolumn{5}{|c|}{$-\mathrm{cmol}_{\mathrm{c}} \mathrm{dm}^{-3}$} & $\mathrm{H}_{2} \mathrm{O}$ \\
\hline & 7,12 & 11,00 & 0,37 & 0,08 & 3,03 & 2,20 & 0,44 & 5,98 \\
\hline
\end{tabular}

${ }^{\mathrm{I}} \mathrm{MO}$ - matéria orgânica. 
pela equação proposta por Nascimento et al. (2002), onde: $\mathrm{AF}=0,826^{*} \mathrm{~L}^{1,89}$, sendo $\mathrm{AF}$ a área foliar em $\mathrm{cm}^{2}$ e L a largura de cada folha $(\mathrm{cm})$. Os índices de clorofila $(a$ e $b$ ) foram avaliados somente aos 21 e 36 dias após o transplantio (DAT) utilizando o medidor de clorofila portátil ClorofiLOG $1030^{\circledR}$ (Falker Automação Agrícola, 2008), Todas estas avaliações foram realizadas em condições de campo, de forma a preservar as plantas até o fim do ciclo fenológico.

Os dados foram submetidos à análise de variância, para os dados qualitativos foi aplicado o teste de Tukey, a 5\% de probabilidade e regressão para as doses, utilizando o software SISVAR 5.6 beta (Ferreira, 2011).

\section{RESULTADOS E DISCUSSÃO}

Pela análise de variância dos fatores estudados, observou-se que houve efeito significativo da interação entre as doses e os biofertilizantes, para as variáveis de comprimento de ramo e área foliar. A variável, número de folhas foi afetada de modo isolado pelas épocas de avaliação e pelas doses. Para os parâmetros de diâmetro do caule e clorofila houve significância apenas para o fator época.

Para o comprimento de ramo, ajustou-se ao modelo polinomial quadrático com as doses do biofertilizante II, com alcance máximo de $72,0 \mathrm{~cm}$ na concentração de $14,05 \%$ ( $840 \mathrm{~mL}$ do bio II $+2,24 \mathrm{~L}$ de água). Entretanto, o aumento das doses do biofertilizante I ajustou-se ao modelo linear decrescente, ocorrendo decréscimos acentuados no comprimento do ramo. A dose de 5\% (300 $\mathrm{mL}$ do bio I $+2,7 \mathrm{~L}$ de água) do biofertilizante I representou o maior comprimento do ramo $(63,9 \mathrm{~cm})$ (Figura 1A). Para o número de folhas (Figura 1B) em relação às doses dos biofertilizantes, os resultados foram crescentes até a dose máxima de 13,5\% $(810 \mathrm{~mL}$ de bio $+1,89 \mathrm{~L}$ de água) que corresponde a 39 folhas.

$\mathrm{O}$ alongamento do ramo principal associado ao maior número de folhas mostra que a diversidade de nutrientes essenciais presentes nos biofertilizantes quando usados na dose adequada contribuíram para o maior desenvolvimento vegetal, semelhante ao observado por Shams (2018), que obteve um maior comprimento das plantas em resposta à pulverização foliar com Lithovit ${ }^{\circledR}$ ou extrato de leveduras associado a aplicação de $\mathrm{N}$ mineral + $\mathrm{N}$ orgânico em meloeiro. Silva et al. (2016), também contataram melhorias em algumas características comerciais importantes na mesma cultura ao trabalhar com biofertilizante enriquecido em N, e um bioprotetor com a adição de quitosana de fungos C. elegans.

Diversos autores afirmam os efeitos benéficos dos biofertilizantes sobre o crescimento das plantas (comprimento dos ramos, número de folhas, acumulo de massa fresca e seca), quando aplicados no solo via fertirrigação ou via foliar (Freire et al., 2009; Santos et al., 2014; Silva, 2016), sendo um importante suporte nutricional de liberação rápida para as plantas. Corroborando com os resultados obtidos no presente trabalho com relação ao biofertilizante I, Santos \& Trindade (2010), avaliando a cultivar de melancia Crimson Sweet em função da aplicação de diferentes compostos e concentrações, observaram comprimento linear decrescente para a variável de comprimento do ramo. Contudo, segundo Morais \& Maia (2013), avaliando o crescimento do meloeiro adubado com fertilizante orgânico, pode-se verificar que a produção de matéria seca de raiz (MSR), matéria seca da parte aérea (MSPA) e a área foliar (AF) aumentaram com o uso do fertilizante orgânico, enquanto que, para o número de folhas (NF), praticamente não houve diferença.

Para o diâmetro de caule do meloeiro (Figura 2A), o aumento linear crescente foi verificado conforme as épocas de coletas. Já, para o número de folhas, o máximo obtido foi de 45 , alcançado aos 44 DAT, descrito por modelo quadrático (Figura 2B).

$\mathrm{Na}$ fase inicial de desenvolvimento da cultura, os fotoassimilados são direcionados principalmente para a formação do sistema radicular e a partir dos 21 dias, principalmente, passa a ter como dreno preferencial a parte aérea e o crescimento torna-se exponencial até atingir um valor máximo. A diminuição observada do NF no final do ciclo se deve a vários fatores, dentre os quais, a diminuição do fornecimento de água nesta época para aumentar o teor de sólidos solúveis totais nos frutos ( ${ }^{\circ}$ Brix) e também devido a senescência e abscisão foliar induzida pela distribuição preferencial de assimilados em direção aos frutos, conforme citado por Morais et al. (2008) e verificado para o mini melão Cantaloupe por Vendruscolo et al. (2016) e para o meloeiro por Morais \& Maia (2013).

Este decréscimo no fim do ciclo da cultura do meloeiro também foi observado por Morais et al. (2010) e Morais \& Maia (2013), ao relatar que este está associado ao aumento no regime respiratório da planta, provocado 

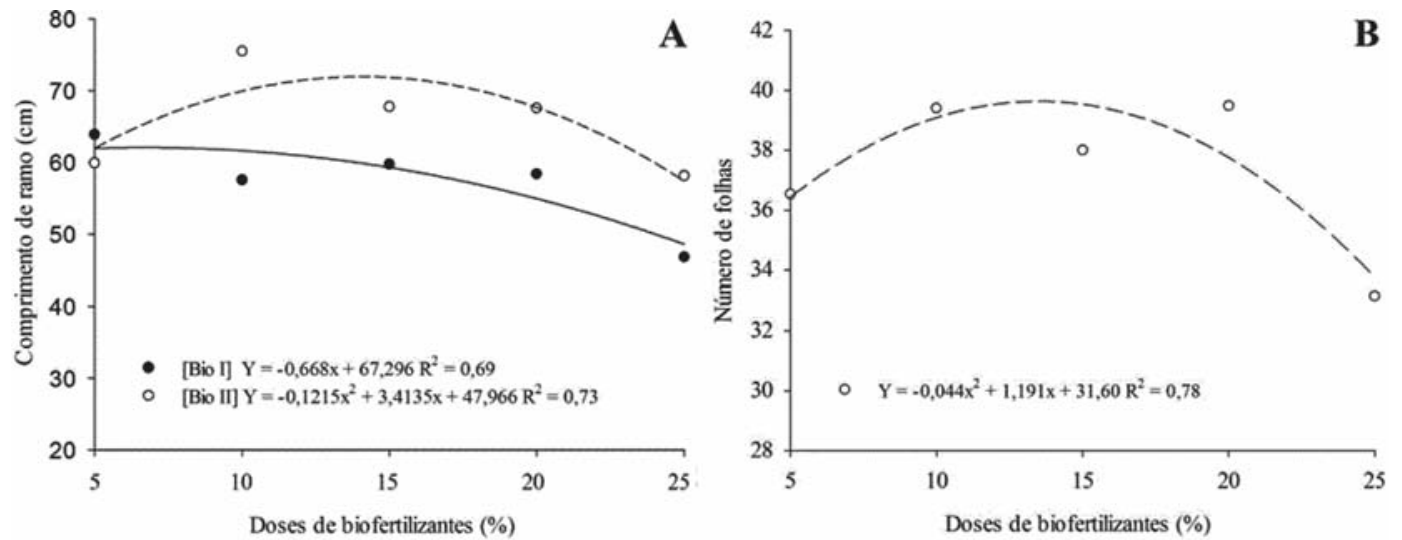

Figura 1 - Comprimento de ramo (A) e número de folhas (B) do meloeiro cv. Gold Mine adubadas com diferentes doses de biofertilizantes. Juazeiro-BA, 2018.
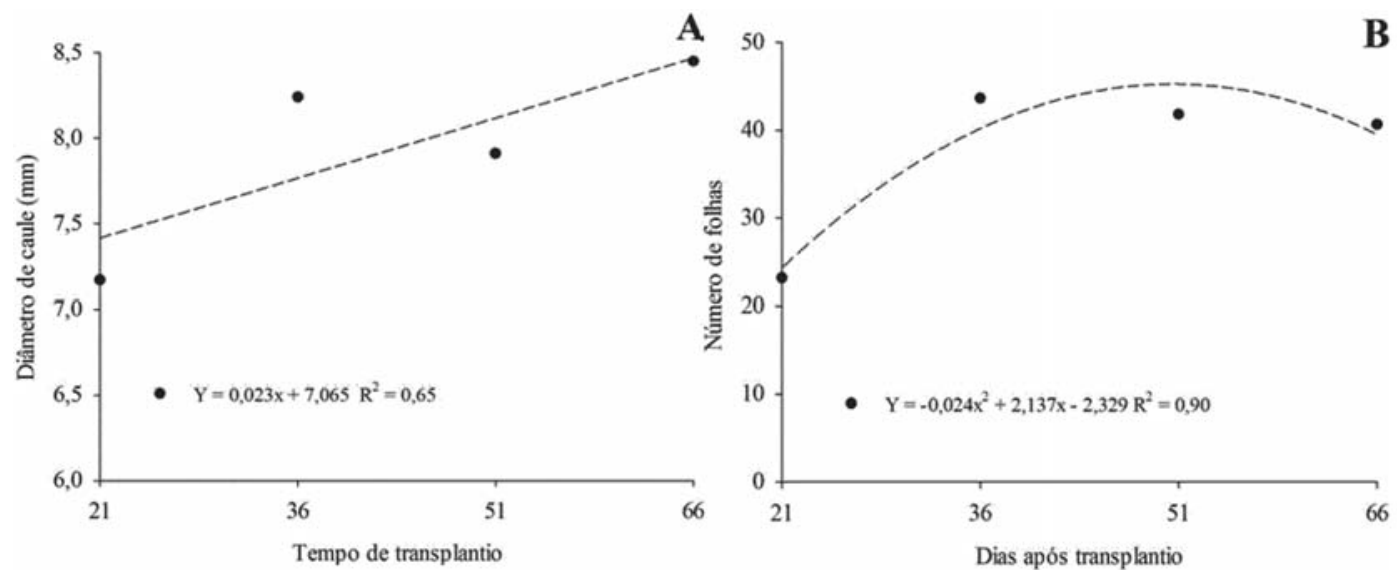

Figura 2 - Diâmetro de caule (A) e número de folhas (B) do meloeiro cv. Gold Mine em função de dias após transplantio. Juazeiro-BA, 2018.

pela perda de biomassa das folhas. As perdas foliares quando muito acentuadas, causam decréscimos na qualidade pós-colheita dos frutos, por estes não terem reservas de amido (Queiroga et al., 2008).

Mendoza-Cortez et al. (2014), constataram que a maior demanda de nitrogênio, acúmulo de matéria seca e atividade fisiológica na cultivar de melão 'Iracema' ocorreu entre 35 e 45 DAT. Esta afirmativa corrobora com os resultados demonstrados na Figura 2b, na qual o maior número de folhas foi obtido aos $44 \mathrm{DAT}$, com ciclo fenológico para o melão de 75 dias, o que implicaria em uma maior área de absorção de radiação e $\mathrm{CO}_{2} \mathrm{e}$ consequentemente, maior taxa fotossintética.

Para área foliar (Figura 3), a interação das doses com os biofertilizantes ajustou-se ao modelo quadrático para o biofertilizante II, sendo que a dose de $18 \%(1,08$ L de bio II + 1,62 L de água) resultou em área foliar máxima de $101,09 \mathrm{~cm}^{2}$. Porém, com as doses do biofertilizante I, o aumento na concentração do produto promoveu decréscimo linear na área foliar, sendo o maior índice de área foliar $\left(88,67 \mathrm{~cm}^{2}\right)$ verificado na dose de $5 \%$ do biofertilizante I ( $300 \mathrm{~mL}$ de bio $+2,7 \mathrm{~L}$ de água).

A área foliar do meloeiro é uma importante medida para avaliar a eficiência quanto à fotossíntese (Dias et al., 2015). Galbiatti et al. (2011) utilizaram efluente de biodigestor proveniente da fermentação de esterco bovino e solução nutritiva no cultivo do meloeiro, alcançando área foliar de $92,80 \mathrm{~cm}^{2}$, que foi superior ao obtido quando comparado com à adubação mineral recomendada para a cultura, no referido trabalho. Porém, 
verifica-se que esse valor ainda foi inferior ao obtido neste trabalho, quando se utilizou o biofertilizante II na dose de $18 \%$.

Segundo Mesquita et al. (2015) e Taiz et al. (2017), as clorofilas representam os pigmentos naturais mais abundantes nos vegetais, sendo um importante parâmetro para estimar o potencial fotossintético das plantas, por sua ligação direta à absorção da luz, transferência de energia fotoquímica para os centros de reação na fotossíntese, crescimento e adaptação aos diversos ambientes.

Pode-se verificar que para os teores de clorofila $a$ e $b$ (Figura 4), houve diferenças estatísticas entre

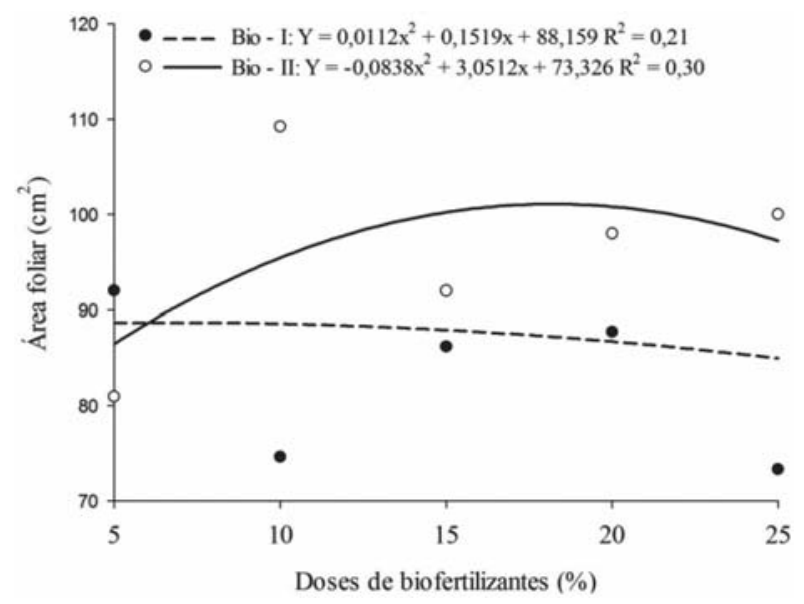

Figura 3 - Área foliar do meloeiro cv. Gold Mine em função da interação dos biofertilizantes com suas respectivas doses. Juazeiro-BA, 2018. as épocas de coletas sendo os maiores valores encontrados aos 36 DAT.

Segundo Freire et al. (2013), a aplicação do biofertilizante bovino em plantas de maracujazeiro, proporcionou aumentos significativos nos teores de clorofila $a$ nas plantas, podendo-se inferir que as plantas conservaram, em parte, a sua capacidade de síntese de clorofila $a$, que é constantemente degradada e ressintetizada ao longo do ciclo das plantas. Ainda nos resultados demonstrados pelos autores, também foi observado que os teores de clorofila $b$ foram inferiores aos de clorofila a. Esses resultados descritos anteriormente foram corroborados com os dados obtidos neste trabalho.

Sabe-se que uma vez absorvido o N é rapidamente assimilado em diversos constituintes celulares, destacando-se os teores de aminoácidos livres totais, proteínas, pigmentos fotossintetizantes (clorofila) segundo descrito por Hawkesford et al. (2012). Estes constituintes irão atuar em inúmeros processos fisiológicos e bioquímicos essenciais ao crescimento e ao desenvolvimento das plantas (KANT, 2017).

O maior índice ocorrido aos 36 DAT para ambas as clorofilas (Figura $4 \mathrm{Ae} \mathrm{B}$ ), pode ser atribuído à maior exigência nutricional das plantas nesta época, pois, de acordo com Neto et al. (2014), para se fazer um programa de adubação na cultura do meloeiro, observou-se, tanto para melões do grupo Amarelo como do grupo Pelede-Sapo, um crescimento lento no início, e maior incremento da parte aérea de 35 a 45 DAT.

Ao avaliar o manejo da fertirrigação em função do uso de curvas de absorção de nutrientes (Silva Junior
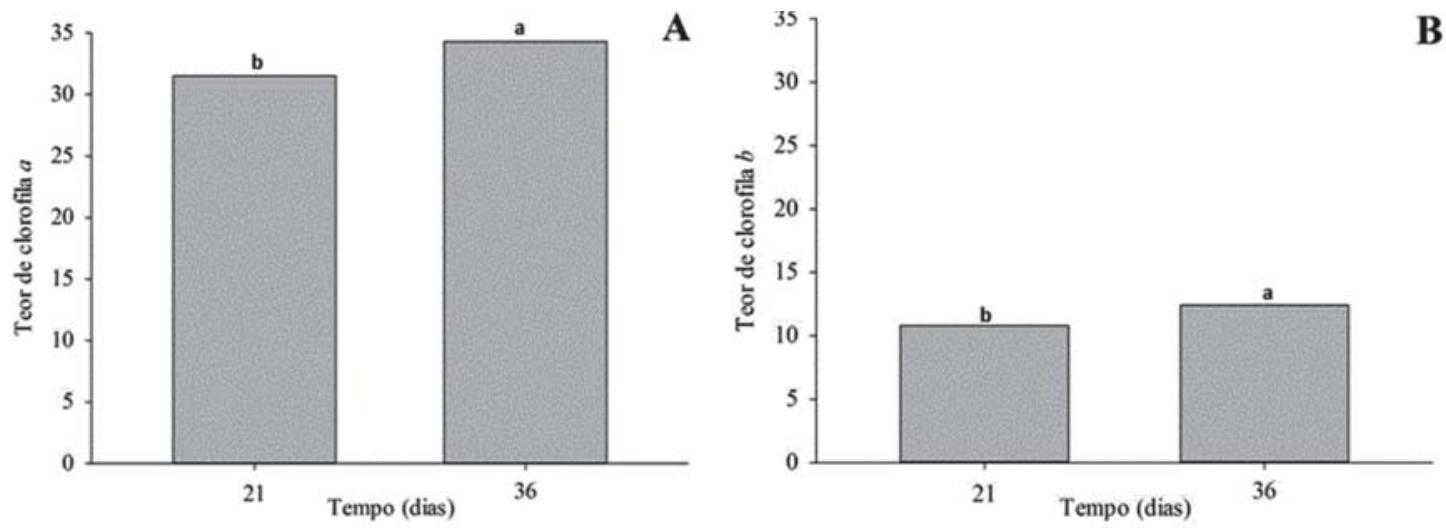

Figura 4 - Teor de clorofila $a$ e $b$ do meloeiro cv. Gold Mine em função de épocas de coletas. Juazeiro-BA, 2018. 
et al., 2010), pode concluir que aos 30 dias, foram obtidas as melhores concentrações de nitrogênio e de potássio. Esses trabalhos indicam que a maior exigência nutricional do meloeiro ocorre nessa fase de crescimento da planta, onde podemos associá-la com a maior demanda pelo processo fotossintético e consequentemente, maior teor de clorofila.

\section{CONCLUSÕES}

A cultura do meloeiro apresenta resposta positiva apenas à aplicação do biofertilizante II.

Recomenda-se para a cultura do meloeiro em sistema orgânico de produção, a adubação com aplicação do biofertilizante II na dose de $15 \%(900 \mathrm{~mL}$ do bio II $+2,1$ L de água), via solo, semanalmente.

\section{LITERATURACITADA}

AGÊNCIA BRASILEIRA DE PROMOÇÃO DE EXPORTAÇÕES E INVESTIMENTOS (ApexBrasil). Exportações do Brazilian Flavors atingem $\$ 49,5$ milhões em exportação. 2017. In: http://www.apexbrasil.com.br/Noticia/ EXPORTACOES-DO-BRAZILIAN-FLAVORSATINGEM-US-49-5-MI (acessado em 09 de Abril de 2019).

ALLEN, R. G.; PEREIRA, L.S; RAES, D.; SMITH, M. Crop evapotranspiration-Guidelines for computing crop water requirements - FAO Irrigation and drainage paper 56. Fao, Rome, v.300, n.9, p.1-281, 1998.

ALVES, M.; CUNHA, W. L. da. A importância da agricultura orgânica na visão social e ecológica. Revistaf@paciencia, Apucarana-PR,v.9, n.1, p.1-7, 2012.

\section{ANUÁRIO BRASILEIRO DA FRUTICULTURA.}

Brasilian fruit yearbook. 2018. In: http:// www.editoragazeta.com.br/sitewp/wp-content/ uploads/2018/04/

FRUTICULTURA_2018_dupla.pdf(acessado em 9 Abril de 2019).

\section{ANUÁRIO BRASILEIRO DA FRUTICULTURA.} Brasilian fruit yearbook. 2017. In: http:// www.editoragazeta.com.br/sitewp/wp-content/ uploads/2017/03/PDF-Fruticultura_2017.pdf (acessado em 02 Agosto de 2018).
DIAS, N. S.; PALÁCIO, V. S.; MOURA, K. K. C. F.; SOUSA NETO, O. Crescimento do meloeiro em substrato de fibra de coco com solução nutritiva salina. Irriga, Botucatu, v.20, n.1, p.1-12, 2015.

EMBRAPA - Empresa Brasileira de Pesquisa Agropecuária. Sistema brasileiro de classificação de solos. $3^{\mathrm{a}}$ ed. Brasília, 2013. 353p.

FARIA L. O.; MELLO M. C.; JÚNIOR, G. S. S; SOUZ, A. G. V.; PELA, A. Doses e épocas de aplicação de nitrogênio na qualidade $e$ produtividade do espinafre (Tetragonia tetragonoides). IV Congresso de Ensino, Pesquisa e Extensão UEG, 2017.

FALKER AUTOMAÇÃO AGRÍCOLA. Manual do medidor eletrônico de teor clorofila (ClorofiLOG / CFL 1030). Porto Alegre, 2008.

FERREIRA, D. F. Sisvar: a computer statistical analysis system. Ciência e Agrotecnologia, v. 35, n. 6, p. 1039-1042, 2011.

FINATTO, J.; ALTMAYER, T.; MARTINI, M. C; RODRIGUES, M.; BASSO, V.; HOEHNE, L. A importância da utilização da adubação orgânica na agricultura. Revista Destaques Acadêmicos, Univates, v.5, n. 4, p.85-93, 2013.

FREIRE, J.L.; CAVALCANTE, O.L.F.; NASCIMENTO, R.N.; REBEQUI, A.M. Teores de clorofila e composição mineral foliar do maracujazeiro irrigado com águas salinas e biofertilizantes. Revista de Ciências Agrárias, v.36, n.1, p.57-70, 2013.

GALBIATTI, J. A.; SILVA, F. G. D.; FRANCO, C. F.; CARAMELO, A. D. Desenvolvimento do feijoeiro sob o uso de biofertilizante e adubação mineral. Engenharia Agrícola, v.31, n.1, p.167177, 2011.

HAWKESFORD, M.; HORST, W.; KICHEY T.; LAMBERS, H.; SCHJOERRING, J.; MøLLER, I. S.; WHITE, P. Functions of macronutrients: potassium. In: MARSCHNER, H. 3.ed. Mineral nutrition of higher plants. Amsterdam: Academic Press, 2012. p.178-189.

INSTITUTO BRASILEIRO DE FRUTAS - IBRAF. Estatísticas. In: Http://www.ibraf.org.br/ estatisticas/Exporta. html (acessado em 21 de julho de 2018). 
LIMA, E. M. C.; CARVALHO, J. A.; VIOL, M. A.; ALMEIDA, R. C.; REZENDE, F. C. Gália melons production in protected environment under different irrigation depths. Soil and Water Engineering, v.37, p.75-83, 2017.

KANT, S. Understanding nitrate uptake, signaling and remobilization for improving plant nitrogen use efficiency. Seminars in Cell \& Developmental Biology, London, v.74, p.89-96, 2017.

KÖEPPEN, W. Climatologia con um estúdio de los climas de la Tierra. México: Fondo de Cultura Economica, 1948. 478p.

LOPES, P. R.; ARAÚJO, K. C. S.; LOPES, I. M.; RANGEL, R. P.; SANTOS, N. F. Revista Espaço de Diálogo e Desconexão, v.8, n.2, p.1-38, 2014.

MAPA - Ministério da Agricultura Pecuária e Abastecimento. Legislação Federal. 2012. In: Http://sistemasweb.agricultura.gov.br (acessado em 27 de julho de 2018).

MENDOZA-CORTEZ, J. W.; CECÍLIO FILHO, A. B.; GRANGEIRO, L. C.; OLIVEIRA, F. H. T. Crecimiento, acumulación de macronutrientes y producción de melón cantaloupo y amarillo. Revista Caatinga, v.27, n.3, p.72-82, 2014.

MESQUITA, A. C.; SOUZA, V.; FERREIRA, K. M.; MORAES, J. P. S.; SOUZA, M. A. Efeito da aplicação de fontes de nitrogênio em plantas de umbuzeiro propagadas via sexuada e assexuada. Revista SODEBRAS, v.10, n.114, p.9-13, 2015.

MORAES, M. D.; OLIVEIRA, N. A. M. Produção orgânica e agricultura familiar: obstáculos e oportunidades. Desenvolvimento

Socioeconômico em Debate, v.3, n.1, p.19-37, 2017.

MORAIS, E. R. C.; MAIA, C. E. Crescimento da parte aérea e raiz do meloeiro adubado com fertilizante orgânico. Revista Ciência Agronômica, v.44, n.3, p.505-511, 2013.

MORAIS, E. R. C.; MAIA, C. E.; NEGREIROS, M. Z.; ARAÚJO JUNIOR, B. B., MEDEIROS, J. F. Crescimento e produtividade do meloeiro Goldex influenciado pela cobertura do solo. Scientia Agraria, v.9, n.2, p.129-137, 2008.
MORAIS, E. R. C.; MAIA, C. E.; NEGREIROS, M. Z.; ARAÚJO JUNIOR, B. B. Crescimento e produtividade do meloeiro Torreon influenciado pela cobertura do solo. Acta Scientiarum Agronomy, v.32, n.2, p.301-308, 2010.

NASCIMENTO, B.; FARIAS, C. H. A.; SILVA, M. C. C. MEDEIROS, J. F.; SOBRINHO, J. E.;

NEGREIROS, M. Z. Estimativa da área foliar do meloeiro. Horticultura Brasileira, Brasília, v.20, n.4, p.64-68, 2002.

Neto, A.P.; Grangeiro, L. C.; Mendes, A. M. S.; Costa, N. D.; Da Cunha, A. P. A. Growth and nutrient accumulation in melon crop in BaraunaRN and Petrolina-PE. Revista Brasileira de Fruticultura, v.36, n.3, p.556-568, 2014.

QUEIROGA, M.; AGUERO, D.; ZAPATA, R.; BUSILACCHI, H.; BUENO, M. Activadores de crecimiento y biofertilizantes como alternativa al uso de fertilizantes químicos en cultivo de chía (Salvia hispanica L.). Energías Renovables y Medio Ambiente, v.35, n.1, p.33-40, 2016.

SANTOS, A. W.; TRINDADE, A. M. G. Analise do crescimento e desenvolvimento de melancia submetida a diferentes doses de esterco de caprino. Agropecuária Técnica, v.31, n.2, p.170-173, 2010.

SHAMS, A. Comparing response of melon (Cucumis melo) to some different growth stimulants (foliar spray). Egyptian Journal of Horticulture, [s.1.], v.45, n.1, p.81-91, 2018.

SILVA JÚNIOR, M. J; DUARTE, S. N.; OLIVEIRA, F. DE A.; MEDEIROS, J. F.; DUTRA, I. Resposta do meloeiro à fertigação controlada através de íons da solução do solo: desenvolvimento vegetativo. Revista Brasileira de Engenharia Agrícola e Ambiental, v.14, p.715-722, 2010.

SILVA, W. O.; STAMFORD, N. P.; SILVA, E. V.; SANTOS, C. E.; FREITAS, A. D. S.; SILVA, M. V. The impact of biofertilizers with diazotrophic bacteria and fungi chitosan on melon characteristics and nutrient uptake as an alternative for conventional fertilizers. Scientia Horticulturae, [s.1.], v.209, n.9, p.236-240, 2016.

TAIZ, L.; ZEIGER, E.; MOLLER, I.; MURPHY, A. Fisiologia e desenvolvimento vegetal. 6.ed. Porto Alegre: Artmed, 2017. 888 p. 
VENDRUSCOLO, E. P.; MONTELO, L. S.; MARTINS, A. P. B.; CAMPOS, L. F. C.; SEMENSATO, L. R.; SELEGUINI, A. Número de folhas por planta e ponto de colheita para produção de mini melão Cantaloupe. Caderno de Ciências Agrárias, v.8, n.3, p.22-27, 2016.
ZAMBERLAM, J.; FRONCHETI, A. Agricultura ecológica: preservação do pequeno agricultor e do meio ambiente. Petrópolis, RJ: Vozes, 2001. 214 p.

Recebido para publicação em 26/10/2018 e aprovado em 10/04/2019. 